\title{
Low signal intensity of motor cortex in SWI sequence: a radiological marker for motor neuron disease?
}

Baixa intensidade de sinal do córtex motor na sequência SWI: um sinal radiológico de doença do neurônio motor?

Afonso Celso Pedrotti Liberato', Victor Hugo Rocha Marussi', José Luiz Pedroso², Acary Souza Bulle Oliveira², Orlando G. Barsottini², Lázaro Luiz Faria do Amaral’

We describe 03 patients with motor neuron disease: one with primary lateral sclerosis (PLS) (Figure 1) and two with amyotrophic lateral sclerosis (ALS) (Figures 2 and 3) whose brain MRI disclosed hypointense signal in precentral gyri gray matter in susceptibility weighted imaging (SWI) in High-Field MRI (3T).

MRI techniques have been used with variable success in identifying upper motor neuron (UMN) involvement in $\mathrm{ALS}^{1}$. Our report also describes similar findings in one patient with PLS. Hypointensity in precentral gyrus gray matter in SWI is presumably related to iron accumulation, proportionally to severity of UMN impairment $^{2,3}$. Recent data have proposed hypointense signal in precentral gyri gray matter as a neuroimaging biomarker for $\mathrm{ALS}^{4}$.
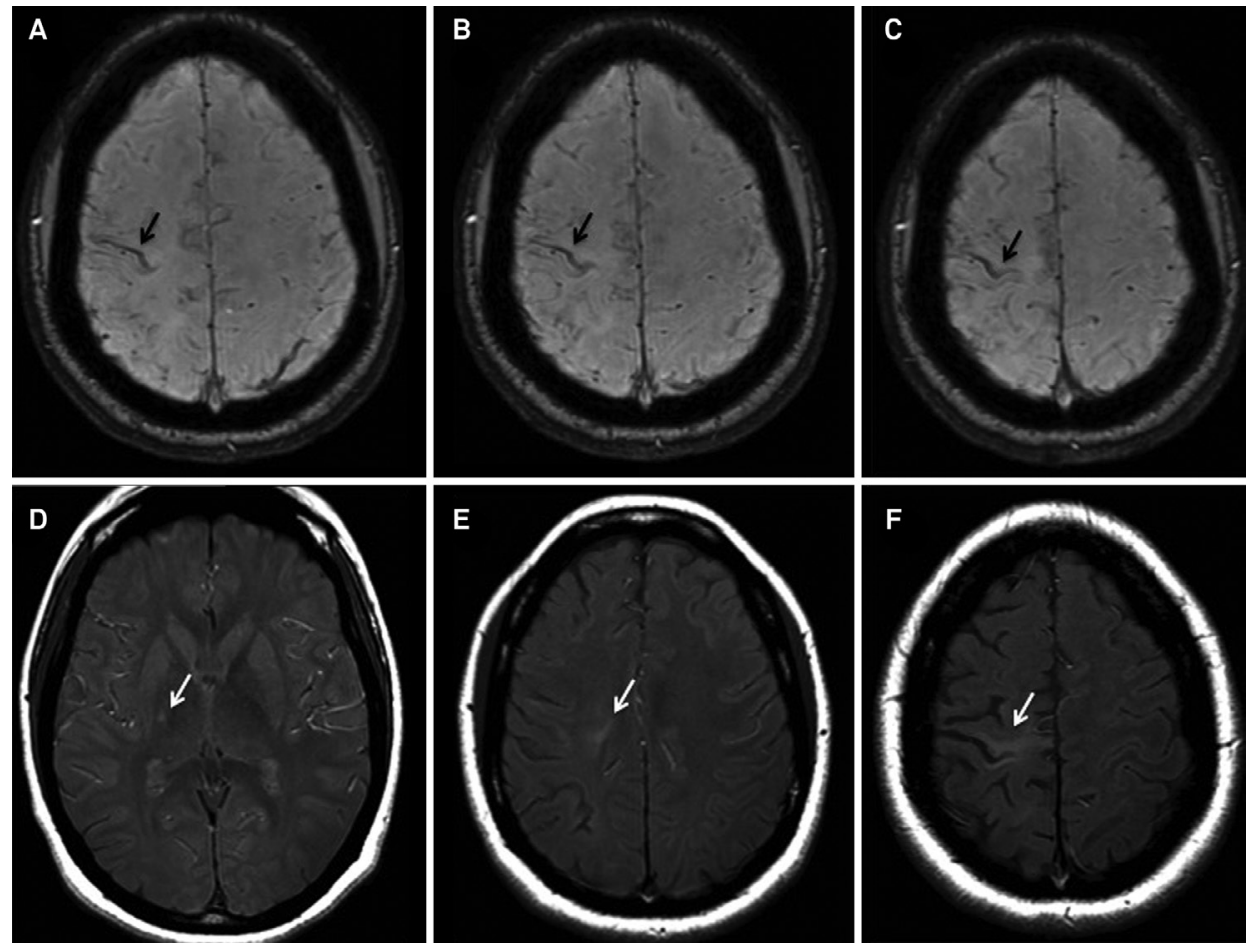

Figure 1. Axial SWI MRI (A, B and C) in a 31 year-old woman with PLS demonstrates linear low signal intensity in right precentral gyrus gray matter (black arrows). Axial T1-weighted magnetization transfer contrast-enhanced (MTC) images (D, E and F) show hyperintense signal along the right corticospinal tract, from the motor cortex until the posterior limb of internal capsule (white arrows). Signs of ipsilateral perirolandic atrophy can also be appreciated.

${ }^{1}$ Hospital Beneficência Portuguesa de São Paulo, Med Imagem, São Paulo SP, Brazil;

${ }^{2}$ Universidade Federal de São Paulo, Departamento de Neurologia, São Paulo SP, Brazil;

Correspondence: Afonso Celso Pedrotti Liberato; Med Imagem, Hospital Beneficência Portuguesa de São Paulo; Rua Maestro Cardim, 407; Liberdade, 01323000 São Paulo SP, Brasil; E-mail: afonsocpl@gmail.com

Conflict of interests: There is no conflict of interest to declare.

Received 23 October 2014; Received in final form 02 December 2014; Accepted 22 December 2015 

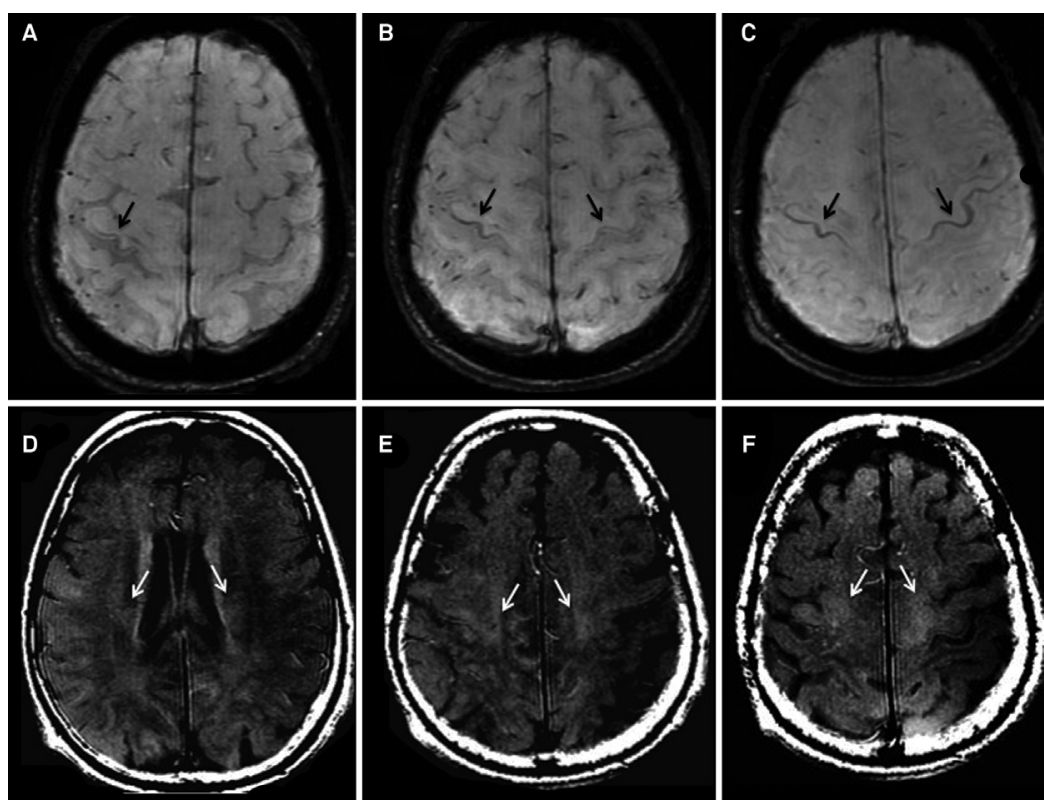

Figure 2. Axial SWI MRI (A, B and C) in a 81 year-old man with ALS demonstrates progressive linear low signal intensities in precentral gyri gray matter (black arrows) over one year, first unilateral and later bilateral. Axial T1-weighted MTC MR images (D, E and F), done at the same period as (C), depicted bilateral hyperintense signal along the cranial segment of corticospinal tract (white arrows).
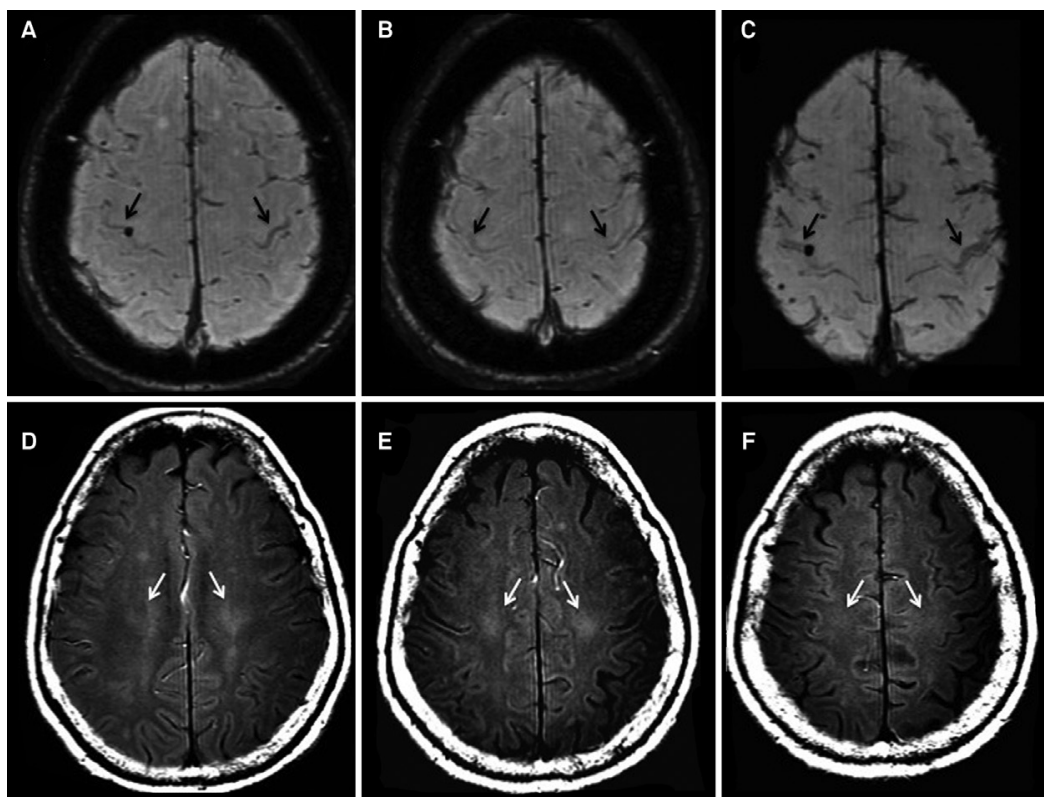

Figure 3. Axial SWI (A and B) and SWI MIP reconstruction (C) MRI in a 76 year-old man with ALS demonstrate bilateral linear hypointensities in precentral gyri gray matter (black arrows). As additional findings, were noticed multiple subcortical small foci of marked low signal intensity in the supratentorial compartment, that was presumed to be due to microhaemorrhages. Axial T1-weighted MTC MR images (D, E and F) show bilateral hyperintense signal along the cranial segment of corticospinal tract (white arrows).

1. Rocha AJ, Maia Júnior ACM. Is magnetic resonance imaging a plausible biomarker for upper motor neuron degeneration in amyotrophic lateral sclerosis/primary lateral sclerosis or merely a useful paraclinical tool to exclude mimic syndromes? A critical review of imaging applicability in clinical routine. Arq Neuropsiquiatr. 2012;70(7):532-9. http://dx.doi.org/10.1590/S0004-282X2012000700012

2. Kwan JY, Jeong SY, Van Gelderen P, Deng H_X, Quezado MM, Danielian LE et al. Iron accumulation in deep cortical layers accounts for MRI signal abnormalities in ALS: correlating
7 tesla MRI and pathology. PLoS One 2012;7:e35241. http://dx.doi.org/10.1371/journal.pone.0035241

3. Yu J, Qi F, Wang N, Gao P, Dai S, Lu Y et al. Increased iron level in motor cortex of amyotrophic lateral sclerosis patients: an in vivo MR study. Amyotroph Lateral Scler Frontotemporal Degener. 2014;15(5-6):357-61. http://dx.doi.org/10.3109/21678421.2014.906618

4. Ignjatović A1, Stević Z, Lavrnić S, Daković M, Bačić G. Brain iron MRI: a biomarker for amyotrophic lateral sclerosis. J Magn Reson Imaging. 2013;38(6):1472-9. http://dx.doi.org10.1002/jmri.24121 